\title{
Sentimentos Infantis em Relação à Deficiência Intelectual: Efeitos de uma Intervenção
}

Children's Feelings About Intellectual Disability: Interventional Effects

Sentimientos de los Niños Sobre la Discapacidad Intelectual: Efectos de una Intervención

\section{Camila Mugnai Vieira}

Universidade Estadual Paulista

Júlio de Mesquita Filho

http://dx.doi.org/10.1590/1982-370301282013 
Resumo: A presente pesquisa descreveu sentimentos de crianças sem deficiência acerca da deficiência intelectual e analisou os efeitos de um programa informativo sobre eles. Participaram do estudo quarenta crianças de duas salas do segundo ano de uma escola estadual de uma cidade do interior paulista. Uma das salas participou como grupo controle. Todas as crianças passaram por pré e pós-testes, na forma de entrevistas individuais sobre o tema. O grupo experimental participou do programa informativo, composto por treze encontros semanais, de uma hora e meia de duração cada, nos quais foram discutidas as limitações e as possibilidades das pessoas com deficiência intelectual, o atendimento especializado, sua escolarização e aspectos familiares e sociais, utilizando estratégias lúdicas e educacionais variadas. Os dados coletados nas entrevistas foram categorizados e analisados em seu conteúdo. O programa possibilitou um melhor entendimento da deficiência intelectual, diminuiu as confusões com outras deficiências e com doenças a ampliou a percepção das habilidades dos sujeitos com deficiência intelectual. Os sentimentos relacionados à comiseração relatados no pré-teste, porém, não diminuíram com o programa, indicando que as informações não foram suficientes para atuar nessa esfera afetiva. Trabalhos futuros devem considerar tais aspectos e buscar estratégias que atinjam aspectos cognitivos, sociais, afetivos e comportamentais.

Palavras-chave: Inclusão escolar. Emoções. Crianças. Retardo mental.

Abstract: This study described the feelings about intellectual disabilities in children without disabilities and examined the effects of an information program about these. The study included 40 children in two classes in the second year of a state school in a city in São Paulo. One of the classes participated as a control group. All children underwent pre- and post-study tests in the form of individual interviews on the subject. The experimental group participated in the information program comprising weekly meetings lasting $13.5 \mathrm{~h}$ in total, in which the limitations and opportunities for people with intellectual disabilities, specialized care, their education, and their family, and social aspects using various recreational and educational strategies were discussed. Data collected from the interviews were categorized and analyzed for their content. The program allowed a better understanding of intellectual disability, reduced confusion with other disabilities and diseases, and increased perception of the abilities of individuals with intellectual disabilities. However, feelings associated with pity reported in the pre-test did not decrease with the program, indicating that the information provided was insufficient for acting on that affective sphere. Future studies should consider these aspects and find strategies for achieving cognitive, social, emotional, and behavioral aspects.

Keywords: School Inclusion. Emotions. Children. Mental retardation.

Resumen: Este estudio describe los sentimientos de los niños sin discapacidad sobre la discapacidad intelectual y examinó los efectos de un programa de información sobre ellos. El estudio incluyó a cuarenta niños de dos salas de aula del segundo año de una escuela pública en una ciudad en el estado de São Paulo. Una de las salas participó como grupo de control. Todos los niños fueron sometidos a pre-y post-test por medio de entrevistas individuales sobre el tema. El grupo experimental participó en el programa informativo por medio de trece reuniones semanales, de una hora y media de duración, donde se discutieron las limitaciones y posibilidades de las personas con discapacidad intelectual, la atención especializada, su educación y los aspectos familiares y sociales, utilizando estrategias lúdicas y educativas variadas. Los datos recogidos de las entrevistas se clasificaron y se analizó su contenido. El programa permite una mejor comprensión de la discapacidad intelectual, disminuyó las confusiones con otras discapacidades y enfermedades y amplió la percepción de las capacidades de las personas con discapacidad intelectual. Sin embargo, los sentimientos relacionados a la conmiseración reportados en el pre-test, no disminuyeron con el programa, lo que indica que las informaciones no fueron suficientes para actuar en esa esfera afectiva. Futuros trabajos deben tener en cuenta estos aspectos y encontrar estrategias que alcancen los aspectos cognitivos, sociales, emocionales y de comportamiento.

Palavras clave: Inclusion Escolar. Emociones. Ninos. Retraso mental. 
1 Ao longo do texto é utilizada a expressão "pessoa, indivíduo ou sujeito com deficiência", de acordo com as proposições de Amaral (1996). Segundo a autora, essa terminologia acentua o caráter dinâmico e social da deficiência, desloca o eixo do atributo do indivíduo para sua condição e também destaca o "sujeito da frase", não colocando a pessoa como sinônimo da deficiência, ressaltando a unicidade do sujeito e sendo mais descritiva que valorativa.

\section{Introdução}

De acordo com Amaral (1998), há um conceito construído socialmente de um "tipo ideal" de ser humano, que, no caso da cultura ocidental recente, vem a ser um "jovem, do gênero masculino, branco, cristão, heterossexual, física e intelectualmente perfeito, belo e produtivo" (Amaral, 1998, p. 14). Percebe-se que é grande o valor dado à perfeição, à estética, à inteligência e à produtividade.

Nesse contexto, o sujeito com deficiência ${ }^{1}$, mais especificamente com deficiência intelectual, representa a imperfeição, a incompletude, relacionada à incapacidade e à improdutividade. Mais que uma fuga ao padrão ideal, psicologicamente, as pessoas com deficiência representam uma ameaça à estabilidade, à sensação de equilíbrio, ao controle e à previsibilidade do ser humano. Representam o estranho, uma diferença extremamente significativa para a maioria das pessoas.

Tudo aquilo que diz respeito às diferenças provoca uma série de sentimentos no ser humano e afeta significativamente as relações interpessoais. No caso das deficiências, são afetadas especialmente as relações entre as pessoas consideradas deficientes e as pessoas sem deficiência. As pessoas e os grupos geralmente têm necessidade de se proteger do que não conhecem, pois o "desconhecido" representa uma ameaça aos padrões já estabelecidos, ao que está estruturado, como seus valores e critérios, normalidade e estética, por exemplo (Saeta, 1999). Em busca de um equilíbrio ou de evitar a desestabilização que o sujeito com deficiência representa, as pessoas criam categorias e classificam-se em grupos, posicionado o outro e a si próprios.

Em razão da grande fragilidade do ser humano, as pessoas têm a necessidade de se considerarem completas, estáveis. O indivíduo com deficiência reflete esta fragilidade, sua incompletude, o que gera angústia e insegurança. Segundo Glat (1995), o estranho, o diferente, chama a atenção e tende a gerar reações como curiosidade, espanto, medo ou repulsa. Para livrar-se dessa sensação, toda a sociedade cria mecanismos sofisticados para colocar tais pessoas à margem da sociedade.

Os encontros entre as pessoas estigmatizadas e as não-estigmatizadas, chamados de encontros mistos por Goffman (1988), são vivenciados como uma interação angustiada por ambas as partes. Segundo o autor, há uma ambivalência de sentimentos que gera muito desconforto, assim esses encontros são evitados. Contudo, quando ocorrem, podem ser carregados de tensão e insegurança. Amaral (1992), por sua vez, nos diz que o indivíduo com deficiência desorganiza, mobiliza e, nessa situação de tensão, pode ocorrer a hegemonia do emocional sobre o racional.

O modo de agir das pessoas nestas situações é tão variado e tão complexo quanto suas concepções, no entanto Goffman (1988) descreve algumas situações possíveis. Aqueles com deficiência, por um lado, podem agir defensivamente, agressivamente, manteremse apáticos, por razões como insegurança quanto à reação dos outros, quanto à aceitação, a reações frente à curiosidade alheia, ao oferecimento de ajudas desnecessárias ou ao não-oferecimento de ajudas importantes e à possibilidade de redução de sua pessoa apenas ao estigma. Contrariamente, as pessoas sem deficiência podem achar que os sujeitos com deficiência sabem o que elas estão pensando, costumam se sentir desconfortáveis por não saber o que dizer e fazer, com receio de constranger ou magoar o outro, podem não querer um contato prolongado para evitar dependência ou vínculo de compromisso, entre outros.

Segundo Denari (2006) e Levison e St'Onge (1999), entre os sentimentos mais comuns experienciados pelas pessoas sem deficiência diante das com deficiência estão o medo, o desconforto e a comiseração ou piedade. Para Levison e St'Onge (1999), o medo pode estar relacionado a muitos aspectos da deficiência, mas quase sempre é baseado em concepções equivocadas, não questionadas. Também pode estar relacionado à representação que ainda se tem do indivíduo com deficiência, relacionando-o à imperfeição 
e à incompletude humana. Assim, a pessoa sente medo de estar na mesma situação que a pessoa com deficiência, uma vez que sua presença indica a possibilidade de qualquer um vir a se tornar um sujeito com deficiência. E isso é extremamente aterrorizante, tendo em vista que a condição do indivíduo com deficiência na maioria das vezes é entendida como uma vivência de perdas em geral: perdas de amigos, empregos, lazer, mobilidade, sexualidade. O medo também pode estar relacionado ao mito do contágio, já descrito anteriormente, como se pelo contato alguma característica da deficiência pudesse ser transmitida. Também é possível pensar no medo do "estigma de cortesia", ou seja, de também ser tratado pela sociedade como estigmatizado em função da relação estabelecida com uma pessoa com deficiência (Goffman, 1988). Além desses, pode haver o medo da exigência de obrigação ou de sentirse responsável pela pessoa com deficiência a partir de uma aproximação. De todo modo, o sentimento de medo parece dificultar a visão e interação com a pessoa completa por trás do estigma.

O sentimento de desconforto é muito comum e parece ser fruto do conjunto de outros sentimentos negativos gerados no momento dos encontros, como medo, culpa, ansiedade. Além disso, parece estar relacionado com a sensação de não se saber como reagir, o que falar e fazer, desconhecendo as possíveis reações do outro, já descritas por Goffman (1988). Assim, geralmente, tal desconforto leva à evitação, ou seja, ao afastamento das possibilidades desses encontros.

Um sentimento dos mais comuns é a comiseração, mais frequentemente relatada como "pena" ou "dó". Esse sentimento deve ser considerado natural, desde que não seja a atitude predominante e não defina o indivíduo como um todo. A visão predominante do sujeito com deficiência para que esse sentimento se destaque é a de uma pessoa triste, sem perspectivas, sem habilidades. Tal reação das pessoas geralmente provoca vergonha nos indivíduos com deficiência, levando-os a um isolamento ainda maior. $\mathrm{O}$ sentimento de pena parece evidenciar uma relação de superioridade e inferioridade, diferentemente do sentimento de compaixão, que pode indicar empatia e deve ser de alguma forma estimulado entre todas as pessoas, assim como a cooperação, que deve ser incentivada, diferentemente da superproteção, que deve ser evitada (Levison \& St'Onge, 1999).

Vários autores da psicologia em diferentes vertentes, como Bleger, em 1977, e Freud, em 1926, por exemplo, defendem a ideia de que diante de uma situação tensa ou de perigo, os indivíduos, ou a personalidade total, tende a buscar manter o equilíbrio psíquico, eliminado as fontes de ameaça, insegurança e ansiedade. Segundo tais autores, nessas situações, nas quais parece difícil lidar com a realidade, são acionados "mecanismos de defesa", os quais seriam as estratégias utilizadas pela personalidade para se livrar da situação de tensão. Esse processo é inconsciente, no sentido de não ser percebido e descrito diretamente pelos indivíduos que os vivenciam, faz parte do funcionamento normal da personalidade humana, mas geralmente levam a uma limitação da dinâmica interacional.

Amaral (1992), baseada em teorias psicanalíticas, utilizou-se do conceito de "mecanismos de defesa" para descrever as possíveis reações das pessoas frente à deficiência e à diferença e à ameaça ao equilíbrio que esta representa. Segundo a autora, entre os principais mecanismos de defesa estaria o "ataque", isto é, a agressão contra aquele que foge ao padrão esperado. Outro mecanismo seria a "fuga", que pode se dar especialmente pela rejeição do sujeito com deficiência, expressa por meio do abandono ou do afastamento dele, de sua superproteção ou da negação da deficiência. A negação pode ser pela simulação, ou seja, fingir que a deficiência não existe, atenuando-se o problema, minimizando-o ou compensando-o com outras características do indivíduo.

As pesquisas com crianças que investigam seus sentimentos em relação aos indivíduos com deficiência apresentam resultados diversos, alguns indicando sentimentos ambivalentes, 
como os descritos na literatura apresentada anteriormente. Bussab (1997), por exemplo, discute estudos experimentais sobre comportamentos pró-sociais em crianças. A empatia é vista em muitos estudos como mediadora de comportamentos pró-sociais e de ajuda. Porém, altos níveis de angústia diante do sofrimento do outro revelaram-se prejudiciais aos comportamentos de ajuda, tendo as crianças a tendência de focalizar-se em seus próprios sentimentos em detrimento do outro nestas situações. No entanto, outras pesquisas descritas pela autora mostram resultados contrários e relacionam a ansiedade diante do sofrimento do outro com uma preocupação com o mesmo e um aumento do comportamento de ajuda.

Marques, Moreira, Maria e Passos (1997), em uma pesquisa realizada com crianças da rede pública municipal de Juiz de Fora- MG sobre suas concepções a respeito da deficiência, observaram que as crianças relacionam a deficiência à falta, ausência e especificamente a um corpo imperfeito. Muitas delas apresentaram uma visão do sujeito com deficiência como extremamente dependente, inclusive para realizar atividades básicas.

Vayer e Roncin (1989) realizaram um estudo com crianças de quarta e quinta séries de classes com alunos com deficiências. Em seus relatos, as crianças participantes disseram que as crianças com deficiência precisam ser ajudadas; apresentando certa culpabilidade nas respostas, algumas se sentindo capazes de ajudar e outras não. Outro tema comum foi o medo, especialmente relacionado à reação da sociedade à deficiência. As crianças não se sentiam superiores aos colegas com deficiência, recusavam-se a fazer um julgamento negativo sobre o comportamento deles e a deficiência era vista como injustiça.

2 Pesquisa financiada pela Coordenação de Aperfeiçoamento de Pessoal de Nível Superior (CAPES).
O presente trabalho é um recorte da uma dissertação de mestrado de Vieira (2006)², que teve como objetivos analisar concepções, sentimentos e atitudes de crianças sem deficiência sobre a deficiência intelectual e a inclusão e avaliar os efeitos de um programa informativo que trata da temática. Neste artigo serão apresentados os resultados referentes aos sentimentos relatados pelas crianças com relação à deficiência intelectual e os efeitos da intervenção sobre os mesmos.

\section{Método}

Quarenta crianças sem deficiência participaram do estudo. Elas estudavam em duas salas do segundo ano (20 de cada sala), de uma escola estadual de uma cidade do interior paulista, que atendia alunos com deficiência intelectual em classes especiais, salas de recursos e salas comuns. Os alunos de uma das salas formaram o "grupo experimental" (GE) e, os da outra sala participaram como "grupo controle" (GC).

Para a coleta de dados, foi utilizado um roteiro semiestruturado para entrevistas com as crianças, composto por dez questões abertas, algumas com desdobramentos, elaborado com base em instrumentos de estudos anteriores (Baleotti \& Omote, 2003; Ferreira, 1998; Martins, 1999), tendo passado por um estudo preliminar, antes de sua utilização. O roteiro abordava os seguintes blocos temáticos: (1) caracterização dos participantes quanto ao contato com pessoas com deficiência e ao acesso a informações sobre o tema; (2) concepções sobre deficiência intelectual; (3) sentimentos em relação à deficiência intelectual; (4) escolarização das crianças com deficiência intelectual; (5) aspectos relacionados à inclusão e à amizade entre crianças com e sem deficiência; (6) vida adulta do sujeito com deficiência intelectual; (7) família e deficiência intelectual; (8) livre expressão sobre o tema.

Todas as crianças passaram por um pré e um pós-teste, na forma de entrevistas individuais sobre o tema.

O pré e o pós-teste seguiram o mesmo procedimento: iniciaram-se por uma contextualização da temática para as crianças por meio de um vídeo que apresentava crianças com deficiência em seu cotidiano escolar (Ferreira, 1998). Após este, cada criança desenhou, ela própria e uma criança com deficiência intelectual (como ela conhecia ou 
imaginava que fosse). A partir do desenho e do roteiro de entrevistas, as crianças e estas foram entrevistadas individualmente com objetivo de investigar o contato anterior e atual da criança com pessoas com deficiências, o acesso a informações sobre o assunto e suas concepções, atitudes e sentimentos com relação à deficiência intelectual e à inclusão. As entrevistas tiveram duração de cinco a vinte minutos, aproximadamente, e foram gravadas.

O grupo experimental participou do programa informativo, baseado no programa de Ferreira (1998), descrito no livro Aprendendo sobre a deficiência intelectual: um programa para crianças. O programa foi composto por treze encontros semanais de aproximadamente uma hora de duração. Entre os conteúdos trabalhados no programa estão: a contextualização da deficiência intelectual na diversidade humana, a explicação da deficiência intelectual, de acordo com as possibilidades de compreensão das crianças e a visão do indivíduo com deficiência intelectual como capaz, com habilidades, com necessidades especiais e limitações, mas podendo exercer sua cidadania e ter uma vida plena, com relacionamentos afetivos e produtividade. Além disso, apresentou conteúdos relacionados à necessidade de intervenção especializada precoce, relacionamentos familiares e escolarização. Os encontros aconteceram na própria escola, no horário de aula das crianças e com a participação da professora da sala. Para os encontros, foram preparadas atividades lúdicas e educativas variadas e materiais diversos, como fantoches, revistas, livros infantis, roupas e objetos para teatro, entre outros.

As entrevistas com as crianças foram transcritas na íntegra. A pesquisadora realizou várias leituras das entrevistas e as respostas foram organizadas em categorias, a partir da análise de conteúdo. Após isso, o material foi encaminhado a dois juízes para a codificação das respostas, segundo as categorias propostas pela pesquisadora, mas independentemente da organização feita por ela e independentemente um do outro. O maior índice de concordância obtido foi de $87,3 \%$.
Alguns dados obtidos nas entrevistas passaram por uma análise estatística para a verificação da significância das diferenças entre os grupos. Aplicou-se a Prova de Fisher, comparando-se o pré-teste do grupo experimental com o préteste do grupo controle. Todos os resultados indicaram não haver diferença significativa entre os grupos no pré-teste. Posteriormente, aplicou-se a Prova de Fisher para comparar o pós-teste do grupo experimental com o pós-teste do grupo controle, visando verificar se as diferenças apresentadas pelos grupos no pós-teste eram significativas. Para todos os cálculos estatísticos realizados nas diferentes etapas de análise dos dados, foram registrados os "valores de p". O nível de significância adotado em todos os testes foi de $\mathrm{a}=0,05$, ou seja, consideraram-se diferenças significativas aquelas cujo "valor de p" obtido foi menor que 0,05 .

\section{Resultados e Discussão}

Primeiramente serão apresentados alguns dos resultados obtidos nas entrevistas com as crianças. Não serão apresentados de forma quantitativa, mas de um modo geral, para a contextualização da mesma. Em seguida, serão apresentados mais detalhadamente os resultados referentes aos relatos de sentimentos das crianças em relação à deficiência intelectual.

A maioria das crianças disse ter contato com pessoas com deficiência. Não é possível afirmar que se referiram a pessoas com deficiência intelectual, pois as crianças evidenciaram desconhecimento sobre o tema. A escola é o local de maior contato, indicando que a presença de classes especiais, de salas de recursos e de alguns alunos com deficiência em salas comuns proporciona uma oportunidade para essa interação mista.

Muitas crianças afirmaram nunca terem tido acesso a informações sobre o tema. Entre as que tiveram, a televisão foi a fonte de informações mais citada, revelando o potencial da mídia para a construção de concepções mais adequadas e atitudes mais positivas quanto às pessoas com deficiência, devido ao grande alcance que possui. Os dados também enfatizam a necessidade de a mídia 
ampliar sua preocupação com os conteúdos veiculados, cuidando para não transmitir mensagens que mantenham estereótipos e preconceitos, nem que incentivem apenas a piedade e a caridade, no lugar da empatia e da solidariedade. Os resultados evidenciam a necessidade de pais e professores envolverem-se mais com o tema, procurando se informar sobre o assunto e rever suas próprias concepções, com o intuito de transformar o tema em algo natural, que faça parte do cotidiano escolar e familiar.

As crianças, de modo geral, não apresentaram atitudes preconceituosas ou de rejeição em relação às pessoas com deficiência. Apesar disso, constatou-se um grande desconhecimento da deficiência intelectual, sendo esta confundida com outras deficiências, como a física e a sensorial, e relacionada a doenças. No último caso, várias crianças indicaram uma concepção do sujeito com deficiência como frágil, não podendo se expor a situações sociais comuns, pois foram consideradas por tais crianças como fatores de risco à saúde dos indivíduos com deficiência.

Em sua maioria, as crianças pareceram perceber mais facilmente as deficiências que apresentam características de maior visibilidade, requerendo o uso de equipamentos ou evidenciando diferenças marcantes no corpo. Mesmo assim, já parecem perceber as distinções de pessoas com deficiência intelectual, apesar de terem dificuldade de compreendê-la, remetendo-se a comportamentos e traços da aparência que observam.

As crianças que passaram pelo programa apresentaram um maior entendimento de aspectos importantes da deficiência intelectual, como a dificuldade de aprendizado, o desenvolvimento mais lento e possíveis dificuldades de adaptações ao meio. O programa permitiu a compreensão das limitações da deficiência intelectual, diminuindo as confusões com outras deficiências e a relação intelectual e a observar sua relação com o meio social.

O programa parece ter proporcionado a várias crianças uma maior observação do meio e das dificuldades enfrentadas pelos sujeitos com deficiência, não apenas em virtude da deficiência, mas por sua relação com a sociedade, percebendo o tratamento recebido pelas pessoas com deficiência e a necessidade de apoios e adaptações.

Além das limitações, o programa parece ter proporcionado às crianças uma percepção das habilidades e possibilidades dos sujeitos com deficiência intelectual e uma observação maior de similaridades entre eles e as pessoas sem deficiência, o que pode fazer com que os indivíduos com deficiência deixem de ser considerados estranhos e as crianças aumentem as iniciativas de aproximação a eles.

Apesar das inúmeras mudanças observadas com a intervenção, os relatos de sentimentos das crianças não sofreram mudanças significativas, como será mostrado e discutido em seguida. As crianças foram questionadas sobre os sentimentos que vivenciam quando vêem ou ouvem falar sobre pessoas com deficiência intelectual.

É importante ressaltar que os sentimentos vivenciados pelas pessoas em todas as situações e no contato com a deficiência não são estáticos e únicos. Na realidade, geralmente são experienciados muitos sentimentos conjuntamente, inclusive alguns ambivalentes, em um mesmo momento, e muitos de difícil descrição. Assim, para essa análise, considerou-se o sentimento que a criança pôde descrever na situação de entrevista, entendendo que esse sentimento provavelmente teria certo destaque no momento de contato direto ou indireto com a deficiência, mas seria vivenciado em conjunto com muitos outros. As respostas estão indicadas na Tabela 1.

No pré-teste, a maioria das crianças de ambos os grupos $(65 \%$ do GE e $70 \%$ do GC) indicou ter sentimentos de comiseração diante de pessoas com deficiência intelectual. O relato das crianças apresenta a expressão de sentimentos de "dó, pena e tristeza", nas palavras destas. Tais sentimentos foram relacionados por algumas crianças a aspectos da própria deficiência, como a 
Tabela 1. Sentimentos em relação às pessoas com deficiência intelectual

\begin{tabular}{lcccccccc}
\hline Respostas & \multicolumn{2}{c}{ GE-Pré } & \multicolumn{2}{c}{ GE-Pós } & \multicolumn{2}{c}{ GC-Pré } & \multicolumn{2}{c}{ GC-Pós } \\
\hline & $\mathrm{f}$ & $\%$ & $\mathrm{f}$ & $\%$ & $\mathrm{f}$ & $\%$ & $\mathrm{f}$ & $\%$ \\
Sentimentos relacionados à & 1 & 5 & 3 & 15 & 2 & 10 & 3 & 15 \\
alegria, amizade, solidariedade* & & & & & & & & \\
Sentimentos de comiseração* & 13 & 65 & 15 & 75 & 14 & 70 & 13 & 65 \\
Sentimentos de medo & 1 & 5 & 0 & 0 & 2 & 10 & 2 & 10 \\
Não expressaria sentimentos & 5 & 25 & 2 & 10 & 2 & 10 & 2 & 10 \\
TOTAL & 20 & 100 & 20 & 100 & 20 & 100 & 20 & 100 \\
\hline
\end{tabular}

Questão norteadora: O que você sente quando vê ơu ouve falar em crianças com "deficiência intelectual"?

* categorias analisadas estatisticamente

Pré-teste: $\mathrm{GE}=\mathrm{GC}(\mathrm{p}=1) /$ Pós-teste: $\mathrm{GE}=\mathrm{GC}(\mathrm{p}=1)$

3 Os nomes das crianças são fictícios e os relatos literais. falta de membros, dificuldade intelectual; por outras, às incapacidades ou dificuldades das crianças com deficiências para realizar algumas atividades:

Fico triste porque eu queria ver eles brincarem. Porque não anda, não se mexe, tem que ficar sentada na cadeira de rodas. - GE-pré - Eduardo ${ }^{3}$

Fico triste, porque essas crianças ficam doentes, daí não podem se divertir, não podem fazer mais coisas. - GE-pré - Daniel

Dó. Porque elas não podem fazer quase tudo, nós pode. Não podem brincar muito porque pode acontecer alguma coisa, elas se machucarem. - GC-pré - Wilson

Sinto dó porque nós brinca, corre, pula e eles não podem fazer nada. Quase nada. Pode brincar um pouquinho de bola. Mas, tem gente que não tem jeito de andar, tem que ficar deitado na cama. - GC-pré - Allan

Uma dor e uma dó. Porque eu gosto das pessoas que podem andar, falar, dessas eu tenho dó. - GC- pré - Silvana

Os outros sentimentos indicados pelas demais categorias referem-se ao medo, à alegria, à amizade e à solidariedade. No entanto, determinadas crianças disseram não experienciar e não expressar sentimentos diante de pessoas com deficiência.
Algumas crianças expressaram um desejo de que a deficiência não existisse ou pudesse ser curada ou reparada. A deficiência dos outros é sentida como injustiça:

Sinto tristeza porque não pode ninguém ficar assim, todo mundo tem que viver feliz. - GE-pré - Silvana

Os sentimentos de medo foram relatados pelas crianças de diferentes formas, usando expressões como "agonia" e o "medo" propriamente dito. Algumas crianças relataram o medo de que as pessoas com deficiência fizessem algo de ruim com elas, as agredissem; outras crianças indicaram o medo de uma contaminação pela deficiência, relacionando-a com doenças contagiosas. O medo de crianças da contaminação pela deficiência também foi encontrado no estudo de Glat (1995) e é discutido na literatura como um dos mitos construídos pela sociedade desinformada acerca da deficiência (Amaral, 1998; Levison \& St'Onge, 1999). Os relatos a seguir indicam esse sentimento de medo, nos dois sentidos, que parece estar relacionado a uma concepção negativa da deficiência:

Eu tenho medo de eles fazerem alguma coisa. Ninguém me falou isso, eu que sinto. - GE-pré - Marli

Sinto um pouquinho de medo, dá arrepio assim, vai que elas me batem ou me beliscam e não sabe. - GC-pré-Melina 
Fico meio estranho. Não sei por quê.... Às vezes eu, por exemplo, eu via lá no shopping, daí eu passo para o outro corredor. Não sou muito chegado assim não. Sinto uma coisa estranha... Saio muito de perto. Outro dia, passou um filme que o menino era deficiente intelectual, aí, o pai e a mãe dele também pegou essa doença... Senti medo. Quando tava passando o filme, eu saí de perto, fui do outro lado da rua para não assistir... Tenho medo que eu pego a doença. Eu acho que pega. Se a pessoa passar perto, ficar muito perto de mim, eu acho que pega. - GC-pré- Luís

Esses relatos de sentimentos de medo foram dados por uma criança do GE e duas do GC, no pré-teste. Quanto aos sentimentos de alegria, amizade e vontade de ajudar, foram citados apenas por uma criança do GE e duas do GC, no pré-teste.

Entre as crianças que disseram não expressar sentimento algum, as respostas mais comuns foram aquelas que utilizaram expressões como "normal" e "nada" referindo-se aos sentimentos experienciados diante das pessoas com deficiência intelectual ou do tema. Essas respostas foram dadas por $25 \%$ das crianças do GE e $10 \%$ do GC, no pré-teste.

Os resultados encontrados no pré-teste com relação aos sentimentos das crianças estão de acordo com a literatura, que indica a comiseração como um sentimento bastante comum de pessoas sem deficiência diante de pessoas com deficiência (Amaral, 1998; Levison \& St'Onge, 1999). O sentimento de piedade geralmente está relacionado a uma visão da pessoa com deficiência como infeliz, incapaz, sem amigos. Essa é a concepção em relação ao indivíduo com deficiência intelectual ainda vigente em nossa sociedade, reforçada pela mídia, que relaciona a deficiência ao apelo emocional e financeiro, como já foi discutido. Alguns estudos encontraram relatos de crianças que caracterizaram as pessoas com deficiência a partir de atributos negativos (Martins, 1999), apresentando uma visão do aluno com deficiência como dependente, improdutivo, necessitado de ajuda para todas atividades básicas (Marques et al., 1997) e sem perspectivas para o futuro (Magiati, Dockrell \& Logotheti, 2002).

No pós-teste, houve um pequeno aumento das respostas que indicaram sentimentos de comiseração no GE (de 10\%) e uma pequena diminuição no GC (de 5\%). Exemplos de relatos do GC, no pós-teste, são apresentados a seguir.

Um pouco de tristeza porque eles não podem aproveitar a vida, brincar de basquete, andar de bicicleta, não pode fazer um monte de coisas. Mas, o pai tem respeito com eles, então eles podem ser felizes. - GC-pós - Carlos

Tristeza, porque o número de deficientes é muito triste, tem bastante. No Brasil, nos Estados Unidos tem um monte. As coisas que a gente faz e eles não conseguem fazer me deixa triste. GC-pós - Daiana

Uma diferença observada nas respostas das crianças do GE, no pós-teste, na forma de explicações sobre seu sentimento de comiseração, merece atenção. Como explicação para seus sentimentos de piedade, as crianças apontam para a audiência social, para a reação das outras pessoas e da comunidade em geral frente à deficiência, reações essas que são entendidas pelas crianças como geradoras de segregação e maus tratos. Algumas se remetem a situações reais vivenciadas e outras imaginam certas situações possíveis de ocorrer. Outras ainda relatam seus sentimentos de piedade e dizem que se o tratamento recebido ou a reação das pessoas fossem diferentes, seus sentimentos seriam outros:

Eu fico com muita dó mesmo. Têm que ficar só dentro de casa o dia inteiro porque senão... elas tinham que vir para escola, senão elas não vão aprender e não vão conseguir entender o que têm que fazer. Se tá na escola, daí tá tudo bem, porque ela fica saindo. Não pode ficar dentro de casa. Senão, na época que é para ela trabalhar, ela pensa que é para ficar dentro de casa. Se estiver saindo, daí eu posso até ficar um pouco feliz... porque elas estão saindo... têm que ficar fora de casa. - GE-pós - Victor 
Me sinto mal, muito triste. Ainda mais quando esse meu amigo "lelé" passou lá com o pai dele e de tanto ele gritar, o pai dele deu um tapa nele, ele começou a chorar, eu me senti muito mal. Eu tava andando de bicicleta, olhei para baixo e quase bati num carro... o pai podia conversar com ele, falar: "pára de fazer isso aí, senão alguém vai achar que eu não cuido direito de você". Quando não tá maltratando, eu sinto feliz, aí eu brinco com elas. - GE-pós - Eduardo

Triste, porque, às vezes, têm crianças que não querem brincar com elas porque nunca aprenderam como ajudar quem é deficiente. - GE-pós - Vanessa

Eu não sinto nada, acho que elas podem brincar, pular. Fico meio tristinho porque têm algumas pessoas que maltratam elas, chamam elas de feias. Nunca vi, mas eu sei que têm pessoas que não gostam de deficientes. GE-pós - Daniel

Um pouco meio triste, porque às vezes elas não têm amigos... Elas têm alguns... mas, às vezes, as pessoas magoam elas, depois elas não gostam e às vezes, nem sabem. - GE-pós - André

O sentimento de injustiça quanto à deficiência é novamente relatado por uma criança do GE, no pós-teste:

Sinto dó porque eu queria que nunca tinha existido essa deficiência para todo mundo ser como as pessoas normais. Pode até ser feliz, mas, tenho dó porque eles têm essa deficiência. Se eles não tivessem, estaria tudo bem, porque essa deficiência, ninguém pode ter. - GE-pós - Silvana

Quanto aos relatos de sentimentos de medo, estes não apareceram entre as crianças do GE, no pós-teste. No GC, mantiveram a mesma porcentagem nos pré e pós-testes (10\%). Exemplos desses relatos:

Medo. Mas, não sei, porque um me bate, um me abraça. O Ricardo é um pouco deficiente, sabia? Porque ele bagunça demais, fala demais. - GC-pós - Guilherme
Me dá uma agonia... me dá ânsia de vômito, dor de cabeça... Eu acho que eu não gosto disso, não sei por que. Se elas melhorarem, podem ser felizes, se der um remédio ou alguém que já morreu pode tirar o braço ou uma perna e colocar nela. - GC-pós - Luís

Quanto aos relatos que indicavam sentimentos de alegria, vontade de ajudar, houve um aumento de $10 \%$ no GE e de $5 \%$ no GC do pré para o pós-teste. Todavia, estes representaram apenas 15\% das respostas de ambos os grupos, no pós-teste. Os relatos abaixo ilustram essas categorias de respostas:

Eu acho que elas são legais, que elas brincam com nós do mesmo jeito. Sinto amor por elas. - GE-pós - Davi

Sinto que eu quero ajudar, sendo amigo dele, ensinando coisas para ele. GC-pós - Ellen

Fico alegre, quero brincar com elas. GC-pós - Leandro

Eu fico querendo ajudar, porque eu gosto. - GC-pós - José

No pós-teste, $10 \%$ das crianças de cada grupo disseram que "não expressariam sentimentos", não sentiriam "nada".

Como pode-se perceber na Tabela 1, comparando-se o GE com o GC no pós-teste com relação às crianças que indicaram sentimentos relacionados a alegria, amor, vontade de ajudar e as crianças que indicaram sentimentos de comiseração, a diferença entre os grupos não é estatisticamente significante $(p=1)$.

Os resultados encontrados no pós-teste contestam as hipóteses levantadas de que entre as crianças que passaram pelo programa, um maior número apresentaria sentimentos de alegria, amizade, e que o número de crianças relatando sentimentos de comiseração diminuiria. Os dados contradizem, ainda, os resultados encontrados por Ferreira (1998), que aplicou o programa informativo que deu origem ao utilizado na presente pesquisa em 148 crianças e obteve resultados nos quais o sentimento de piedade diminuiu consideravelmente após o mesmo. 
As hipóteses foram levantadas considerando-se que, após o programa, as crianças apresentariam maior compreensão da deficiência intelectual, uma visão das habilidades e potencialidades do sujeito com deficiência, além de suas limitações, e que essa mudança nas concepções pudesse estar relacionada a outros sentimentos que não a comiseração.

Os dados discutidos até o momento indicaram que após o programa as crianças, de fato, apresentaram concepções e atitudes mais positivas referentes à deficiência, mas entre os relatos dos sentimentos, um número ainda maior de crianças demonstrou a comiseração. Algumas hipóteses podem ser levantadas sobre esses dados. Uma delas se refere a possíveis mensagens transmitidas ao longo do programa que podem ter sido entendidas pelas crianças no sentido de "piedade". Durante o programa, atitudes de solidariedade e empatia foram bastante incentivadas. Embora tenha havido a preocupação em não direcionar essas atitudes à caridade e a favores, mas a uma maior aproximação e aceitação social, pode ser que as crianças dessa idade, que ainda estão iniciando a observação e a expressão verbal de seus sentimentos, tenham relacionado tais aspectos a sentimentos de comiseração. Isso pode ter ocorrido, sobretudo porque esse tipo de sentimento é bastante comum e incentivado socialmente, como indicador de sensibilidade por parte de quem o relata.

A análise desses dados e a elaboração de futuros trabalhos devem considerar também que as crianças fazem parte de um contexto mais amplo, onde os sentimentos de comiseração ainda são incentivados.

Outra hipótese refere-se à própria intensidade do aspecto emocional no encontro com a diversidade, especialmente a deficiência, sobrepondo os elementos cognitivos. A temática frequentemente gera angústia e sentimentos ambivalentes. A pessoa com deficiência revela-nos a fragilidade do humano, como apontam Amaral (1992) e Glat (1995), entre outros. As crianças podem vivenciar esses sentimentos, mesmo tendo ampliado a compreensão da deficiência intelectual, indicando que provavelmente as informações não foram suficientes para transformar seus sentimentos.

Ainda pode-se considerar o fato de as crianças ao longo do programa terem acesso a informações, por meio de relatos, livros, vídeos e outros materiais, da reação da sociedade frente à deficiência. As crianças puderam, de alguma forma, ter acesso a conteúdos que esclareciam, além da condição da deficiência em si, aspectos sociais, que indicaram que em vários contextos os sujeitos com deficiências são rejeitados, excluídos. Essa hipótese parte dos relatos das crianças que disseram experienciar sentimentos de comiseração referindo-se à audiência social. Além da injustiça de a criança ter nascido ou se tornar uma pessoa com deficiência, apresentada no relato de algumas crianças e relatada também na pesquisa de Marques et al. (1997), as crianças parecem perceber as injustiças sociais vivenciadas pelos sujeitos com deficiência. Vayer e Roncin (1999) encontraram relatos de crianças que temiam a reação da sociedade diante dos indivíduos com deficiência, entendendo que isso pudesse magoá-los ou prejudicá-los, o que estaria de acordo com os dados encontrados.

Diante desses dados, é importante considerar que tais sentimentos de comiseração são bastante comuns diante dos indivíduos com deficiência. É essencial, como alerta Levison e St'Onge (1999), ter consciência destes e não permitir que eles paralisem a ação e a busca por mudanças. Ao contrário, esses sentimentos podem ser mobilizados em prol dos sujeitos com deficiência.

Assim, deve-se pensar em futuras intervenções que considerem esses dados e busquem trabalhar tais sentimentos junto às crianças, incentivando a empatia e não a piedade. É importante que as crianças conheçam a realidade dos sujeitos com deficiência em nossa sociedade, mas que vislumbrem possibilidades de mudanças.

Segundo alguns estudos discutidos por Bussab (1997), as crianças nessa fase do desenvolvimento tendem a se colocar com facilidade 
no "lugar do outro". A empatia parece estar relacionada a comportamentos pró-sociais em crianças, porém, o excesso de sofrimento alheio pode gerar angústias nas crianças, o que tende a levá-las a focalizar-se em si, em detrimento do outro.

\section{Conclusões}

A maioria das crianças, no pré-teste, relatou sentimentos relacionados à comiseração, que são muito comuns diante do tema. Esperava-se que as crianças que passaram pelo programa relatassem sentimentos diferenciados no pósteste. Entretanto, os sentimentos de piedade não diminuíram com o programa, indicando que as informações não foram suficientes para atuar nessa esfera afetiva. Para justificar suas respostas, as crianças apontaram as impossibilidades de realização de algumas atividades em função da deficiência e a reação da sociedade aos indivíduos com deficiência, identificando que muitas vezes eles são alvo de exclusão e discriminação, o que gera os sentimentos de piedade relatados.

De certa forma, tais sentimentos são compreensíveis, uma vez que são incentivados na sociedade, como demonstradores de sensibilidade e preocupação com o próximo. Além disso, as justificativas de várias crianças indicam desvantagens reais das pessoas com deficiência na realidade da sociedade atual. As crianças dessa idade têm a tendência de se imaginar no lugar do outro e seus sentimentos revelam isso. Apesar de compreensíveis, esses sentimentos não podem paralisar a ação ou levar a condutas que confirmem a dependência, a fragilidade e a incapacidade do dos sujeitos com deficiência intelectual. Trabalhos futuros devem considerar tais aspectos e buscar estratégias que atinjam aspectos cognitivos, sociais, afetivos e comportamentais. 


\section{Camila Mugnai Vieira}

Doutora em Educação pela Universidade Estadual Paulista Júlio de Mesquita Filho, São Paulo - SP. Brasil. Docente da Faculdade de Medicina de Marília, Marília - SP. Brasil. E-mail: camilamugnai@gmail.com

\section{Endereço para envio de correspondência:}

Rua Francisco Moreno, 59. Jardim Estoril. CEP: 17514-370. Marília - SP. Brasil.

Recebido 02/05/2013, Reformulação 29/07/2014, Aprovado 14/11/2014. 


\section{Referências}

Amaral, L. A. (1992). Atitudes, preconceitos, estereótipos e estigma. In Amaral, L. A. O espelho convexo: $\mathrm{O}$ corpo desviante no imaginário coletivo pela voz da literatura infanto-juvenil. Tese de doutorado, Instituto de Psicologia da Universidade de São Paulo (pp. 60-75). São Paulo.

Amaral, L. A. (1996). Deficiência: Questões conceituais e alguns desdobramentos. Cadernos de Psicologia, 1, 3-12.

Amaral, L. A. (1998). Sobre crocodilos e avestruzes: Falando de diferenças físicas, preconceitos e sua superação. In J. G. Aquino (Ed.), Diferenças e preconceito na escola: Alternativas teóricas e práticas (pp. 11 - 30). São Paulo, SP: Summus.

Baleotti, L. R., \& Omote.S. (2003). Atitudes sociais de alunos do Ciclo I do Ensino Fundamental em relação à inclusão: Construção de uma escala infantil. In Anais Eletrônico, V Simpósio em Filosofia e Ciências (CD-ROM). Marília, SP: Universidade Estadual Paulista.

Bleger, J. (1977). Psicologia de la conducta. Buenos Aires: Paidós.

Bussab, V. S. R. (1997). O desenvolvimento de comportamentos pró-sociais na criança: Considerações sobre a natureza dos fatores e dos processos envolvidos. Temas em Psicologia, 3, 19-26.

Denari, F. E. (2006). Adultos deficientes: E agora? In L. A. R. Martins, J. Pires, G. N. L. Pires, \& F. R. L. V. Melo (Eds.). Inclusão: Desafios e perspectivas (pp. 189-224). Petrópolis, RJ: Vozes.

Ferreira, S. L. (1998). Aprendendo sobre a deficiência mental: Um programa para crianças. São Paulo, SP: Memnon.

Freud, S. (1926). Inhibición, sintoma y angustia. In S. Freud. Obras completas (Vol. 3, (pp. 2833-2883). Madri: Biblioteca Nueva.
Glat, R. (1995). Integração dos portadores de deficiência: Uma questão psicossocial. Temas em psicologia, 2, 89-94.

Goffman, E. (1988). Estigma: Notas sobre a manipulação da identidade deteriorada (4a ed.). Rio de Janeiro, RJ: Guanabara.

Levison, L., \& St'Onge, I. (1999). Disability awareness in the classroom: A resource tool for teachers and students. Springfield, III: Charles C. Thomas.

Magiati, I., Dockrell, J. E., \& Logotheti, A. E. (2002). Young children's understanding of disabilities: The influence of development, context and cognition. Applied Developmental Psychology, 23, 409-430.

Marques, L. P., Moreira, E. V., Maria, G. J., \& Passos, N. S. (1997). A concepção infantil da deficiência. Temas sobre Desenvolvimento, 35(6), 8-14.

Martins, G. A. H. (1999). A integração do deficiente na classe comum: $O$ ponto de vista de alunos do ciclo I do ensino fundamental. Dissertação de Mestrado. Programa de pós-graduação em Educação, Faculdade de Filosofia e Ciências, Universidade Estadual Paulista. Marília, Marília, SP.

Saeta, B. R. P. (1999). O contexto social e a deficiência. Psicologia: Teoria e Prática, 1(1), 51-55.

Vayer, P., \& Roncin, C. (1989). A integração da criança deficiente na classe. São Paulo: Manole.

Vieira, C. M. (2006). Programa informativo sobre deficiência mental e inclusão: Efeitos nas atitudes e concepções de crianças não-deficientes. Dissertação de Mestrado, Universidade Federal de São Carlos, São Carlos. 